\title{
Optimization of Succinic Acid Production from Crude Glycerol by Encapsulated Anaerobiospirillum succinicproducens Using Response Surface Methodology
}

\author{
Sasithorn Kongruang1 ${ }^{*}$, Tawiwan Kangsadan ${ }^{2}$ \\ ${ }^{1}$ Bioprocess Engineering and Biotechnology Research Group, Department of Biotechnology, Faculty of \\ Applied Science, King Mongkut's University of Technology North Bangkok 10800, Thailand. \\ ${ }^{2}$ Chemical and Process Engineering, Thai Siridhorn International Thai-German Graduate School of \\ Engineering. King Mongkut's University of Technology North Bangkok 10800, Thailand. \\ * Corresponding author. Tel.: 662-555-2000; email: stk@kmutnb.ac.th \\ Manuscript submitted October 5, 2014; accepted December 12, 2014.
} doi: 10.17706/ijbbb.2015.5.1.11-25

\begin{abstract}
This paper studies the optimization of a batch cultivation process for the production of succinic acidfrom crude glycerol by using Anaerobiospirillum succinicproducens ATCC 29305 encapsulated with sodium cellulose sulfate/poly-dimethyl-diallyl-ammonium chloride. The batch conditions for the flask were optimized by response surface methodology based on a Box-Behnken design. This design was employed to assess the individual and interactive effects of the four main parameters $\mathrm{pH}$, crude glycerol concentration, shaking speed and temperature) on succinic acid production under anaerobic conditions. Results from the response surface analysis showed that the data were adequately fitted by a second-order polynomial model via a quadratic regression relationship. The final mathematical model after eliminating the insignificant terms and refining the succinic acid production was a quadratic model. For the succinic acid yield it was observed that the interactive effect between crude glycerol and shaking speed was statistically significant. Optimization conditions for maximizing the production were as follows: $\mathrm{pH}, 6$; crude glycerol, $40 \mathrm{~g} / \mathrm{L}$; shaking speed, $150 \mathrm{rpm}$; temperature, $39^{\circ} \mathrm{C}$. Under these conditions, the maximal numerical solution of the model gave a predicted succinic acid level of $34.66 \mathrm{~g} / \mathrm{L}$. For the flask, the experimental production of succinic acid was $34.80 \mathrm{~g} / \mathrm{L}$ with a conversion yield (87\%), and a ratio of succinic acid to acetic acid (34:1). Similar experimental results were obtained for the stirred tank bioreactor. Both sets of experimental results were in good agreement with the model predictions.
\end{abstract}

Keywords: Box-Behnken design, crude glycerol, succinic acid, Anaerobiospirillum succinicproducens, encapsulation, response surface methodology.

\section{Introduction}

Although biodiesel has been produced for many years, its production is now increasing rapidly. In the past, production of biodiesel was not encouraged in South East Asia or in Thailand. However, with the reoccurrence of the petroleumcrisis and recent concerns about the effects on global climate of the use of fossil fuels, there is an increased interest in biodiesel. In 2006, the Ministry of Energy of the Royal Thai Government established a policy to increase energy self-dependence. This policy was started by implementing small-scale production of biodiesel in rural communities and then was extended to larger industrial scale production [1]. The method used for biodiesel production is based on a transesterification 
process. This process produces approximately $90 \%$ biodiesel and $10 \%$ glycerol. This glycerol contains a number of impurities which are excessively costly to remove and which make this impure glycerol unsuitable for conversion to commercial-grade glycerol. Many attempts have been made to use microbial fermentation of crude glycerol to produce useful products such as polyhydroxyalkanotes, ethanol, 1, 3-propanediol, 2, 3-propanediol, acetic acid, succinic acid and other renewable products [2]-[4]. Of these products, succinic acid is becoming increasingly useful. It is now being used by several recognized companies as a raw material for producing biodegradable polymer and polybutylene succinate [5]-[7]. There are also chemicals derived from succinic acid, e.g., 1, 4-butanediol, gamma-butyro lactne and tetrahydrofuran, that are useful as antifoam agents and surfactants [8], [9]. Succinic acid can also be used as a precursor for many industrially important chemicals in food, chemical and pharmaceutical industries. It has been predicted that because of raw material cost and potential market size the current petroleum-based process for producing succinic acid will be replaced in the future by a fermentative succinic acid production system.

Glucose and glycerol are commonly used as the substrates for fermentative succinic acid production. Crude glycerol from biodiesel production is an attractive substrate for future development because it is a waste by-product that can give a high succinic acid yield. Further, when compared with glucose, there is a reduced acetic acid formation and the succinic acid can be easily recovered downstream [10]-[12]. There are many bacterial strains that have been extensively studied and found to be successful strains for succinic acid production. These strains include recombinant Escherichia coli, Actinobacillus succinogenes and Mannheimia succiniciproducens [13]. Each of these strains includes a conserved 16 rRNA gene sequence [14]. As shown in the phylogenic tree in Fig. 1, other microbial organisms with this conserved sequence have been reported and registered in the GenBank.

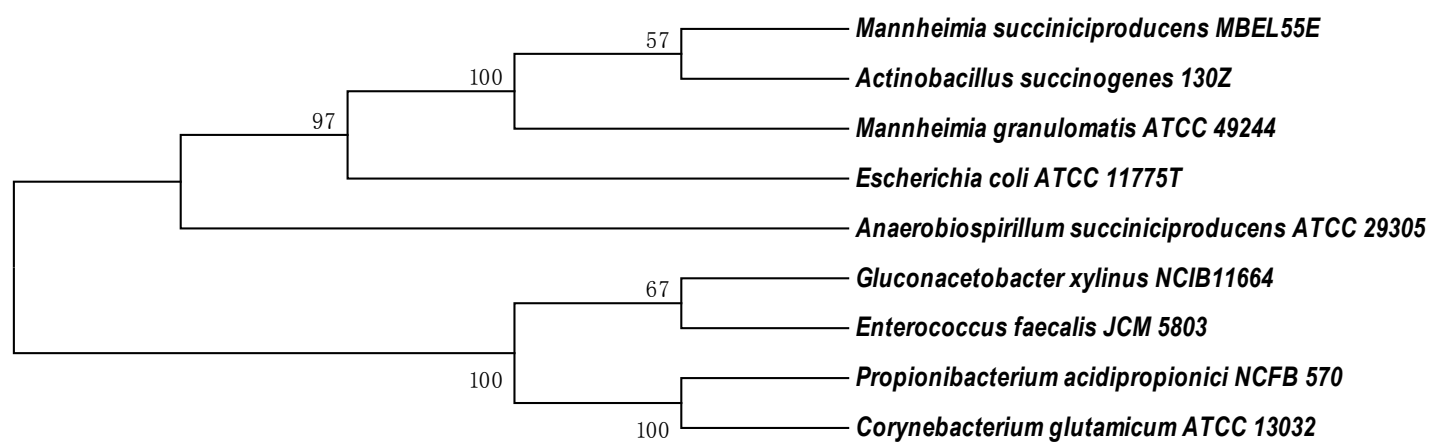

Fig. 1. The phylogeny of the microorganisms of the capnophilic microorganisms, showing the relationships of Anaerobiospirillum succinicproducens ATCC 29305 to its relatives and to the out group of Gluconacetobacterxylinus NCIB11664.

The phylogenetic tree was constructed by the Maximum Composite Likelihood (fDNAml) method. Bootstrap analysis was used in the phylogeny test with UPGMA algorithm statistics analysis and the bootstrap values are placed on the tree branches.

The microbial organisms listed in Fig. 1 include six high yield succinate producers A. succiniciproducens, Mannheimia succiniciproducens, Actinobacillus succinogenes, recombinant E. coli, Corynebacterium glutamicum and Propionibacterium acidipropionici. The chemical pathways for the production of succinic acid by these six organisms and their various derivatives appear to be closely related. With glucose as substrate, they typically produce $52-106 \mathrm{~g} / \mathrm{L}$ of succinic acid with productivities and yields of 1.36-10.4 $\mathrm{g} / \mathrm{L} / \mathrm{h}$ and 0.76-0.88 g/g glucose, respectively [15]. Many investigations have been carried out in attempts to lower the cost of succinic acid production using these organisms. One of the effective succinic acid 
producers is A. succiniciproducens. This is an opportunistic pathogen which is known to cause diarrheal illness but only rarely. This organism has successfully adapted to a wide variety of substrates including synthetic media and industrial wastes such as glucose, galactose, sugar cane molasses, whey, wood hydrolysates, corn-steep liquor, corn stalk, corn straw hydrolysate, corncob hydrolysate and glycerol [16]-[21], [11] has reported a maximum yield of $19 \mathrm{~g}$ succinic acid per liter of glycerol. This maximum yield was obtained when the fermentation broth consisted of glycerol supplemented with yeast extract. However, this yield from glycerol was appreciably lower than the yield obtained from glucose of $29.6 \mathrm{~g}$ succinic acid per liter of glucose.

The above research has been conducted with free-cell fermentation processes. In research into other types of fermentation processes, it has been found that yield can be improved by cell encapsulation [22]. Moreover, cell encapsulation has been used in industry and has many advantages, such as simplified biocatalyst recovery, improved operational stability and a reduced number of steps of downstream processing. In this paper, we are interested in finding optimum fermentation conditions for the production of succinic acid by a cell encapsulation process. The response surface methodology approach is one of the best ways to evaluate and understand interactions between different parameters in a chemical reaction. In this present study, we have attempted to optimize the fermentation process for succinic acid production from encapsulated cells of A. succinicproducens ATCC 29305 used as a biocatalyst. Crude glycerol derived from the Thai biodiesel industry has been used as the sole substrate and the optimization was carried out with a response surface methodology based on a Box-Behnken statistical design. The effects of four independent variables, $\mathrm{pH}$, crude glycerol, shaking speed and temperature, have been investigated.

\section{Materials and Methods}

\subsection{Chemical and Culture Media}

Crude glycerol was obtained from Pathum Vegetable Oil Co., Ltd, Thailand. A preliminary analysis of the raw glycerol showed $84.50 \%$ glycerol, $4.5 \%$ sodium chloride, $9.4 \%$ moisture content and 5,423 ppm soap. Glycerol of 99.5\% purity was obtained from Ajax Finechem Company, Australia. Succinic acid was purchased from Sigma (St. Louis, USA).

\subsection{Preparation of Free-Cell Biocatalyst}

A freeze dried ampoule of A. succinoproducens ATCC29305 was purchased from the American Type Culture Collection (Rockville, MD). The growth of this bacteria from the ampoule was initiated on an ATCC medium 593 (chopped meat medium) according to ATCC recommendations. Inoculum was then prepared as follows. The bacteria colonies were transferred from the ATCC medium 593 into 250-mLanaerobic bottles containing preculture medium and with $\mathrm{CO}_{2}$ as a gas phase. The preculture medium was prepared from $80 \mathrm{~mL}$ minimal salts medium AnS1 (composition: $3 \mathrm{~g} \mathrm{~K}_{2} \mathrm{HPO}_{4}, 1 \mathrm{~g} \mathrm{NaCl}, 1 \mathrm{~g}\left(\mathrm{NH}_{4}\right)_{2} \mathrm{SO}_{4}, 0.2 \mathrm{~g} \mathrm{CaCl}_{2} .2 \mathrm{H}_{2} \mathrm{O}$, $0.2 \mathrm{~g} \mathrm{MgCl}_{2} \cdot 6 \mathrm{H}_{2} \mathrm{O}$, and $3 \mathrm{~g} \mathrm{Na}_{2} \mathrm{CO}_{3}$ ) to which was added $5 \mathrm{~g} / \mathrm{L}$ glycerol, $10 \mathrm{~g} /$ Lyeast extract and $5 \mathrm{~g} / \mathrm{L}$ polypeptone. The $\mathrm{pH}$ of the sterile medium was adjusted to 7 and the anaerobic bottles were then incubated at $39^{\circ} \mathrm{C}$ for $48 \mathrm{~h}$.

\subsection{Preparation of Encapsulated Biocatalyst}

Encapsulation of $A$. succinoproducens ATCC 29305 was prepared aseptically with modification according to the method of Zhao et al., [23]. A solution of sodium cellulose sulfate (NaCS)/poly-dimethyl-diallyl-ammonium chloride (PDMDAAC) was prepared by adding 5\% (w/v) NaCS and $8 \%(\mathrm{w} / \mathrm{v})$ PDMDAAC and mixing thoroughly before sterilizing in autoclave at $121{ }^{\circ} \mathrm{C}$ for $15 \mathrm{~min}$. The seed culture of free-cells was prepared by inoculating free cells into $80 \mathrm{ml} \mathrm{AnS}_{1}$ medium at $39{ }^{\circ} \mathrm{C}$ under anaerobic conditions and then allowing an exponential growth phase of $15 \mathrm{~h}$. Cells were then recovered 
after centrifuging $12,000 \mathrm{~g}$ for $20 \mathrm{~min}$ at $4{ }^{\circ} \mathrm{C}$ and rinsing twice with $0.85 \%$ saline solution. Cells were then mixed with NaCS solution under stirring conditions and PDMDAACS was then added drop by drop. Microcapsules were formed at room temperature and then polymerized for 1 hour. The capsules were then rinsed thoroughly with sterile $\mathrm{H}_{2} \mathrm{O}$. The average diameter of NaCS/PDMAAC microcapsules was $2.5 \mathrm{~mm}$. These microcapsules were used as biocatalyst to carry out the fermentation design. The free cell fermentations with the adjusted pH 6.0 of $800 \mathrm{ml}$ of a sterile medium of $20 \%$ crude glycerol were also monitored under $150 \mathrm{rpm}$ shaking incubator at $39{ }^{\circ} \mathrm{C}$. Samples were withdrawn at intervals of $5 \mathrm{~h}$ and analyzed for biomass, succinic acid, acetic acid and residual glycerol.

\subsection{Preparation of Glycerol Substrate and Experimental Design}

The glycerol substrates for the experiments were prepared as shown in Table 1. Crude glycerol was diluted with distilled water to a variety of selected concentrations. $800 \mathrm{~mL}$ of the diluted glycerol solutions were then added to a 1-L Duran flask, sparged with $\mathrm{N}_{2}$ to achieve anaerobic conditions and then autoclaved. The fermentations were placed on a shaking incubator and temperature was set according to the design. The encapsulated microcapsules from $80 \mathrm{ml}$ inoculum suspension were added and $\mathrm{CO}_{2}$ gas was purged.

\subsection{Analytical Methods}

An HPLC system (Waters chromatography division, Milford, MA, USA) was used to perform an HPLC analysis on the fermented sample using a method previously described by Lee,2010 [11]. The sample was analyzed in an ion exchange column (Aminex HPX-87H, $300 \mathrm{~mm} \times 7.8 \mathrm{~mm}$ ) using $0.012 \mathrm{~N} \mathrm{H}_{2} \mathrm{SO}_{4}$ as the mobile phase. All analytical measurements for glycerol, succinic acid and acetic acid were performed in triplicate. Cell growth was estimated by measuring the absorbance at $600 \mathrm{~nm}$ using a spectrophotometer. Dry cell weight was also measured.

\subsection{Response Surface Methodology}

Response surface methodology was adopted for the production of succinic acid to derive a statistical model for the individual and interactive effects of $\mathrm{pH}$, crude glycerol, shaking speed and temperature. Levels of these factors were optimized for maximum succinic production (the response) from crude glycerol using the Box-Behnken statistical design [24]. Table 1 represents a 29-trial experimental design, where each variable was tested in three different coded levels: low ( -1$)$, middle $(0)$ and high $(+1)$. Succinic and acetic acid in fermentation broth were then measured. Four different polynomial models were tested as possible regression models for the data, namely, a linear model, a 2FI model, a quadratic model and a cubic model. For example, for the second-order polynomial model, it was assumed that the production of succinic acid could be modeled with a quadratic model and the acetic acid could be fitted with the linear regression by equations of the following form:

$$
\begin{gathered}
y_{1}=\beta_{0}+\sum_{i=1}^{4} \beta_{i} X_{i}+\sum_{i=1}^{4} \sum_{j=1}^{4} \beta_{i j} X_{i} X_{j}+\sum_{i=1}^{4} \beta_{i} X_{i}^{2} \\
y_{2}=\sum_{i=1}^{4} \gamma_{i} X_{i}
\end{gathered}
$$

Here, $X_{1}, X_{2}, X_{3}, X_{4}$, are the parameter values for the independent variables (pH, crude glycerol, shaking speed, temperature) as described in Table 1 . The constants $\beta_{0}, \beta_{i}$, and $\beta_{i j}(i, j=1,2,3,4)$ are coefficient estimates for succinic acid production $\left(y_{1}\right)$, where $\beta_{0}$ is an intercept term, $\beta_{i}$ are linear terms, $\beta_{i i}$ are quadratic terms, and $\beta_{i j}$ are interaction production $\left(y_{2}\right)$. The accuracy and general suitability of the above polynomial models could be evaluated by the coefficient of determination $\left(R^{2}\right)$. The experimental data was analyzed terms. They are the corresponding coefficients for the acetic acid using the statistical software, Design-Expert software version 8.0.6 (STAT-EASE Inc., Minneapolis, MN, USA), to carry out a regression 
analysis for the equations and for an evaluation of the statistical significance of the four different polynomial regression models.

Table 1. Experimental Ranges and Level of the Four Fermentation Parameters

\begin{tabular}{ccccc}
\hline \hline Fermentation parameters & Symbol Code & \multicolumn{3}{c}{ Design levels } \\
& & -1 & 0 & 1 \\
\hline $\mathrm{pH}$ & $\mathrm{X}_{1}$ & 6 & 7 & 8 \\
Crude glycerol (g/L) & $\mathrm{X}_{2}$ & 20 & 30 & 40 \\
Shaking speed (rpm) & $\mathrm{X}_{3}$ & 50 & 100 & 150 \\
Temperature $\left({ }^{\circ} \mathrm{C}\right)$ & $\mathrm{X}_{4}$ & 38 & 39 & 40 \\
\hline \hline
\end{tabular}

\section{Results and Discussion}

\subsection{Crude Glycerol Fermentation by Free Cells}

In order to study the cell growth and succinic production profile of the negative spiral-shaped bacteria, $A$. succiniciproducens ATCC 29305 bacteria, the cultivation of free cells was performed on the $20 \%$ crude glycerol as a sole carbon source with a pH of 7 under anaerobic conditions in a $150 \mathrm{rpm}$ shaking incubator at $39^{\circ} \mathrm{C}$. As shown in Fig. 1, the cells grew gradually over the $50 \mathrm{~h}$ fermentation time with a maximum growth rate of $0.041 \mathrm{~g} / \mathrm{L} / \mathrm{h}$ and they produced succinic acid as the major metabolite with acetic acid as a byproduct. Based on the growth and product production results, it was found that succinic acid and acetic acid productions from crude glycerol were the growth-associated product. Calculation of the growth kinetics showed that the maximum specific growth rate $\left(\mu_{\max }\right)$ was $0.217 \mathrm{~h}^{-1}$ with a maximum rate of product formation $1.138 \mathrm{~g} / \mathrm{L} / \mathrm{h}$ and a maximum rate of glycerol consumption of $1.138 \mathrm{~g} / \mathrm{g} / \mathrm{h}$. The maximum succinic acid production rate of $0.569 \mathrm{~g} / \mathrm{L} / \mathrm{h}$ was detected during the first period of fermentation time $(4 \mathrm{~h})$ and the acetic acid production rate was then $0.062 \mathrm{~g} / \mathrm{L} / \mathrm{h}$. The maximum biomass production rate of 0.802 $\mathrm{g} / \mathrm{L}$ was recorded during the $40 \mathrm{~h}$ fermentation time. At the end of the fermentation time, the succinic acid concentration had reached $15.48 \mathrm{~g} / \mathrm{L}$. The average succinic to acetic acid ratio was found to be 22.64 during the 5 to $50 \mathrm{~h}$ fermentation time. At the end of $50 \mathrm{~h}$ fermentation, approximately $30 \%$ of crude glycerol remained (Fig. 2).
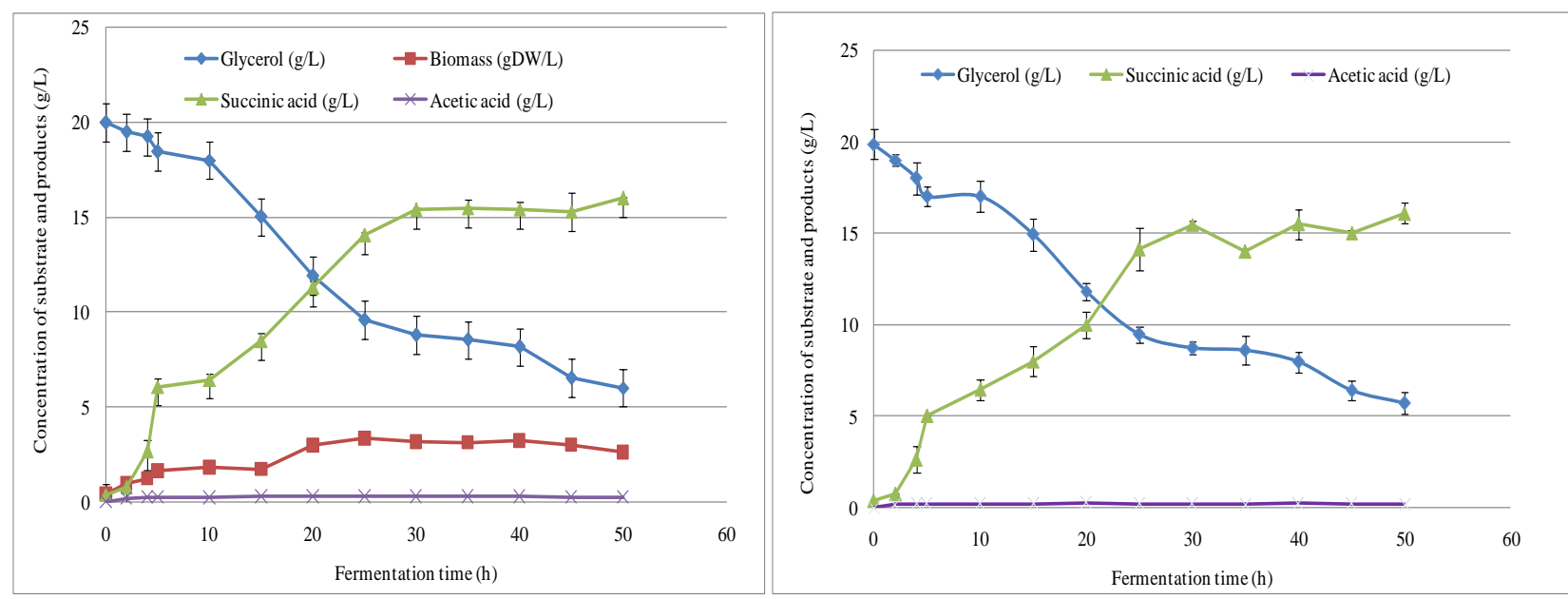

Fig. 2. Anaerobic batch fermentations of (a) free cells and (b) immobilized cells of Anaerobiospirillum succiniciproducens ATCC 29305.

In the present work, we found that the yield of succinic acid production from crude glycerol was approximately $20 \%$ lower than that reported by Lee et al., who obtained a succinic acid yield of up to $19 \mathrm{~g} / \mathrm{L}$ 
under anaerobic batch cultivation from free cells of $A$. succiniciproducens ATCC 29305 using glycerol as a carbon source. Time courses for the succinic acid production of the free cells is presented in Fig. 2.

\subsection{Crude Glycerol Fermentation by Immobilized Cells}

In order to pinpoint the critical factors affecting both cell growth and succinic acid production in immobilized A. succiniciproducens, experiments were carried out using a range of values of the important culture conditions for the succinic acid fermentation from crude glycerol. These culture conditions were as follows: $\mathrm{pH}$, crude glycerol concentration, shaking speed and temperature. The parameters for the runs were set according to the Box-Behnken design (BBD) (Table2).

Table 2. Box-Behnken Design with the Actual Values for Succinic and Acetic Acid Production

\begin{tabular}{|c|c|c|c|c|c|c|}
\hline Run & $\begin{array}{l}\text { Factor } 1 \\
\mathrm{X}_{1}: \mathrm{pH}\end{array}$ & $\begin{array}{c}\text { Factor } 2 \\
\mathrm{X}_{2} \text { :Crude } \\
\text { glycerol }(\mathrm{g} / \mathrm{L})\end{array}$ & $\begin{array}{c}\text { Factor } 3 \\
\mathrm{X}_{3}: \text { Shaking } \\
\text { speed (rpm) }\end{array}$ & $\begin{array}{c}\text { Factor } 4 \\
\mathrm{X}_{4}: \text { Temperature } \\
\left({ }^{\circ} \mathrm{C}\right) \\
\end{array}$ & $\begin{array}{c}\text { Response 1: } \\
\text { Y }_{1} \\
\text { Succinic acid } \\
(\mathrm{g} / \mathrm{L})\end{array}$ & $\begin{array}{c}\text { Response 2: } \\
\text { Y2 } \\
\text { Acetic acid } \\
(\mathrm{g} / \mathrm{L}) \\
\end{array}$ \\
\hline 1 & 8 & 40 & 100 & 39 & 22.00 & 1.62 \\
\hline 2 & 7 & 40 & 100 & 38 & 30.20 & 1.49 \\
\hline 3 & 7 & 30 & 150 & 38 & 20.60 & 1.77 \\
\hline 4 & 7 & 40 & 150 & 39 & 31.80 & 1.07 \\
\hline 5 & 8 & 30 & 50 & 39 & 15.10 & 1.99 \\
\hline 6 & 6 & 40 & 100 & 39 & 34.80 & 2.00 \\
\hline 7 & 6 & 30 & 100 & 40 & 22.50 & 1.45 \\
\hline 8 & 8 & 30 & 150 & 39 & 14.30 & 2.23 \\
\hline 9 & 8 & 20 & 100 & 39 & 12.90 & 1.63 \\
\hline 10 & 8 & 30 & 100 & 38 & 16.80 & 1.78 \\
\hline 11 & 7 & 30 & 100 & 39 & 16.80 & 1.78 \\
\hline 12 & 7 & 40 & 50 & 39 & 22.00 & 1.48 \\
\hline 13 & 7 & 40 & 100 & 40 & 23.60 & 1.39 \\
\hline 14 & 7 & 20 & 50 & 39 & 12.50 & 2.74 \\
\hline 15 & 6 & 30 & 150 & 39 & 22.23 & 1.67 \\
\hline 16 & 7 & 30 & 150 & 40 & 18.60 & 1.80 \\
\hline 17 & 7 & 20 & 100 & 40 & 14.32 & 2.76 \\
\hline 18 & 6 & 30 & 50 & 39 & 20.19 & 1.83 \\
\hline 19 & 6 & 30 & 100 & 38 & 25.50 & 1.51 \\
\hline 20 & 6 & 20 & 100 & 39 & 20.04 & 2.31 \\
\hline 21 & 7 & 20 & 150 & 39 & 14.12 & 2.95 \\
\hline 22 & 7 & 30 & 50 & 40 & 19.90 & 2.48 \\
\hline 23 & 7 & 20 & 100 & 38 & 15.90 & 2.48 \\
\hline 24 & 7 & 30 & 100 & 39 & 18.80 & 2.14 \\
\hline 25 & 7 & 30 & 100 & 39 & 17.20 & 2.30 \\
\hline 26 & 7 & 30 & 100 & 39 & 16.20 & 2.29 \\
\hline 27 & 8 & 30 & 100 & 40 & 16.89 & 2.52 \\
\hline 28 & 7 & 30 & 50 & 38 & 16.70 & 2.45 \\
\hline 29 & 7 & 30 & 100 & 39 & 19.30 & 2.35 \\
\hline
\end{tabular}

The experimental data were then analyzed by fitting the polynomial regression models: linear, 2FI, quadratic and cubic polynomials using the Design-Expert statistical software version 8.0.6. We found that the quadratic response model can correctly describe the production behavior of this system after considering all the linear terms, square terms, and linear by linear interaction items. Three different tests 
such as the sequential model sum of squares, lack of fit tests, and model summary statistics were then carried out to check the four different models. Table 3 shows the results of the statistical tests for the regression results for succinic acid fermentation using encapsulated A. succiniciproducens's cells. The table shows that the regression coefficient was the highest $\left(R^{2}=0.8726\right)$ for the quadratic model with a minimum standard deviation (2.15). Table 4 shows the results of analysis of variance tests of significance of the quadratic polynomial model. As shown in Table 4, the analysis of variance (ANOVA) confirmed that the quadratic form of the model satisfactorily explained the relationship between the various factors and that it was not necessary to use a cubic model.

Table 3. Summary of Statistical Tests: Sequential Model Sum of Squares, Lack of Fit Tests, and Model Summary Statistics

\begin{tabular}{|c|c|c|c|c|c|c|}
\hline \multicolumn{7}{|c|}{ Sequential Model Sum of Squares [Type I] } \\
\hline Source & $\begin{array}{l}\text { Sum of } \\
\text { Squares }\end{array}$ & $\mathrm{df}$ & $\begin{array}{c}\text { Mean } \\
\text { Square }\end{array}$ & $\begin{array}{c}\mathrm{F} \\
\text { Value }\end{array}$ & $\begin{array}{c}p \text {-value } \\
\text { Prob > F }\end{array}$ & Remark \\
\hline Mean vs Total & 11273.92 & 1 & 11273.92 & & & \\
\hline Linear vs Mean & 677.77 & 4 & 169.44 & 25.56 & $<0.0001$ & \\
\hline 2FI vs Linear & 42.20 & 6 & 7.03 & 1.08 & 0.4089 & \\
\hline Quadratic vs 2FI & 68.66 & 4 & 17.16 & 4.98 & 0.0104 & Suggested \\
\hline Cubic vs Quadratic & 35.10 & 8 & 4.39 & 2.01 & 0.2058 & Aliased \\
\hline Residual & 13.12 & 6 & 2.19 & & & \\
\hline Total & 12110.78 & 29 & 417.61 & & & \\
\hline \multicolumn{7}{|l|}{ Lack of Fit Tests } \\
\hline Source & $\begin{array}{l}\text { Sum of } \\
\text { Squares }\end{array}$ & $\mathrm{df}$ & $\begin{array}{c}\text { Mean } \\
\text { Square }\end{array}$ & $\begin{array}{c}\mathrm{F} \\
\text { Value }\end{array}$ & $\begin{array}{c}\text { p-value } \\
\text { Prob > F }\end{array}$ & Remark \\
\hline Linear & 152.01 & 20 & 7.60 & 4.30 & 0.0833 & \\
\hline $2 \mathrm{FI}$ & 109.81 & 14 & 7.84 & 4.44 & 0.0803 & \\
\hline Quadratic & 41.15 & 10 & 4.12 & 2.33 & 0.2157 & Suggested \\
\hline Cubic & 6.05 & 2 & 3.02 & 1.71 & 0.2905 & Aliased \\
\hline Pure Error & 7.07 & 4 & 1.77 & & & \\
\hline \multicolumn{7}{|c|}{ Model Summary Statistics } \\
\hline Source & $\begin{array}{l}\text { Std. } \\
\text { Dev. }\end{array}$ & R-Squared & $\begin{array}{c}\text { Adjusted } \\
\text { R-Squared }\end{array}$ & $\begin{array}{l}\text { Predicted } \\
\text { R-Squared }\end{array}$ & PRESS & Remark \\
\hline Linear & 2.57 & 0.8099 & 0.7782 & 0.7188 & 235.330 & \\
\hline $2 \mathrm{FI}$ & 2.55 & 0.8603 & 0.7827 & 0.6121 & 324.583 & \\
\hline Quadratic & 1.86 & 0.9424 & 0.8848 & 0.7036 & 248.082 & Suggested \\
\hline Cubic & 1.48 & 0.9843 & 0.9268 & -0.0540 & 882.057 & Aliased \\
\hline
\end{tabular}

As is shown in Table 4, the significant terms in the quadratic model are: $\mathrm{pH}$, crude glycerol, shaking speed, the interaction term between crude glycerol and shaking speed and the quadratic term for crude glycerol, where as temperature $(p=0.146)$ is not significant. The quadratic model was then refitted using only the significant terms as the independent parameters. The results are shown in Tables 5 and 6 . The resulting ANOVA for the reduced quadratic model (Table 6) summarizes the analysis of variance of each response and shows the significant model terms. The F-value of 16.35 implies that the model is significant (at $p<0.0001)$. Values of "Prob $>$ F" ( $p$ values) less than 0.05 indicated that the model terms were significant. There is only a $0.01 \%$ chance that a "Model F Value" this large could occur due to noise. In this case $\mathrm{pH}$ and crude glycerol (crude glycerol concentration) were highly significant model terms with $p$-values of $<0.0001$. For the 
reduced model, we found $R^{2}=0.8726$ showing that the model gives a satisfactory fit to the experimental data. The following reduced quadratic model in terms of tested fermentation parameters was obtained.

Table 4. Analysis of Variance Table for Response Surface Quadratic Model for Succinic Acid Production

\begin{tabular}{|c|c|c|c|c|c|c|}
\hline Source & $\begin{array}{l}\text { Sum of } \\
\text { Squares }\end{array}$ & $\mathrm{df}$ & $\begin{array}{l}\text { Mean } \\
\text { Square }\end{array}$ & $\begin{array}{c}\mathrm{F} \\
\text { Value }\end{array}$ & $\begin{array}{c}p \text {-value } \\
\text { Prob > F }\end{array}$ & Remark \\
\hline Model & 788.63 & 14 & 56.33 & 16.35 & $<0.0001$ & significant \\
\hline A-pH & 186.20 & 1 & 186.20 & 54.06 & $<0.0001$ & \\
\hline B-Crude glycerol & 464.01 & 1 & 464.01 & 134.71 & $<0.0001$ & \\
\hline C-Shaking speed & 19.41 & 1 & 19.41 & 5.63 & 0.0325 & \\
\hline D-Temperature & 8.15 & 1 & 8.15 & 2.37 & 0.1463 & \\
\hline $\mathrm{AB}$ & 8.01 & 1 & 8.01 & 2.33 & 0.1496 & \\
\hline $\mathrm{AC}$ & 2.02 & 1 & 2.02 & 0.59 & 0.4569 & \\
\hline $\mathrm{AD}$ & 2.39 & 1 & 2.39 & 0.69 & 0.4191 & \\
\hline BC & 16.73 & 1 & 16.73 & 4.86 & 0.0448 & \\
\hline $\mathrm{BD}$ & 6.30 & 1 & 6.30 & 1.83 & 0.1977 & \\
\hline $\mathrm{CD}$ & 6.76 & 1 & 6.76 & 1.96 & 0.1830 & \\
\hline $\mathrm{A}^{\wedge} 2$ & 13.28 & 1 & 13.28 & 3.86 & 0.0698 & \\
\hline$B^{\wedge} 2$ & 50.75 & 1 & 50.75 & 14.73 & 0.0018 & \\
\hline$C^{\wedge} 2$ & 1.44 & 1 & 1.44 & 0.42 & 0.5290 & \\
\hline $\mathrm{D}^{\wedge} 2$ & 9.55 & 1 & 9.55 & 2.77 & 0.1181 & \\
\hline Residual & 48.22 & 14 & 3.44 & & & \\
\hline Lack of Fit & 41.15 & 10 & 4.12 & 2.33 & 0.2157 & not significant \\
\hline Pure Error & 7.07 & 4 & 1.77 & & & \\
\hline Cor Total & 836.86 & 28 & & & & \\
\hline
\end{tabular}

Table 5. Stepwise Regression for Response Surface Quadratic Model for Succinic Acid Production

\begin{tabular}{lccccc}
\hline \hline Coefficient Added & t for Ho Estimate & Coeff $=0$ & Prob $>|t|$ & R-Squared & MSE \\
\hline B-Crude glycerol & 6.22 & 5.8 & $<0.0001$ & 0.5545 & 13.81 \\
A-pH & -3.94 & -5.09 & $<0.0001$ & 0.777 & 7.18 \\
B^ $2^{\wedge}$ & 2.5 & 2.77 & 0.0103 & 0.8295 & 5.71 \\
C-Shaking speed & 1.27 & 1.94 & 0.0638 & 0.8526 & 5.14 \\
BC & 2.05 & 1.9 & 0.07 & 0.8726 & 4.63 \\
\hline \hline
\end{tabular}

A normal plot of residuals, which shows how the model satisfies the assumptions of the analysis of variance, is shown in Fig. 3a. The residual plot is approximately a straight line indicating that the residuals follow a normal distribution. A graph of the predicted response values versus the actual response values is shown in Fig. 3b. This graph shows that the quadratic model gives a satisfactory fit to the data because the residuals are small.

\subsection{Effect of Influential Fermentation Parameters}

The three-dimensional response surface curves in Fig. 4-Fig. 7 illustrate the effect of interaction among different fermentation parameters on the production of succinic acid and acetic acid. Fig. 4 shows the effect of the interaction between crude glycerol and $\mathrm{pH}$ on succinic and acetic acid production with other parameters held constant at optimum values for succinic acid production. The figure shows that the optimal $\mathrm{pH}$ value for succinic acid production is 6 and the optimal crude glycerol value is $40 \mathrm{~g} / \mathrm{L}$. The succinic acid production is reduced if the $\mathrm{pH}$ is increased and/or the crude glycerol concentration is decreased. In Fig. 4b, 
the acetic acid production is a minimum of 1.52 at pH 6.0 and crude glycerol $40 \mathrm{~g} / \mathrm{L}$ and the maximum succinic acid: acetic acid ratio of 22.76 occurs at shaking speed of $150 \mathrm{rpm}$ and temperature of $38.67{ }^{\circ} \mathrm{C}$.

Table 6. ANOVA for Response Surface Reduced Quadratic Model

\begin{tabular}{lcccccc}
\hline \hline & Sum of Squares & df & Mean Square & F Value & $p$-value Prob $>$ F & Remark \\
\hline Source & & & & & & significant \\
Model & 730.27 & 5 & 146.05 & 31.52 & $<0.0001$ & $<0.0001$ \\
A-pH & 186.2 & 1 & 186.2 & 40.18 & $<0.0001$ & \\
B-Crude glycerol & 464.01 & 1 & 464.01 & 100.13 & 0.0523 \\
C-Shaking speed & 19.41 & 1 & 19.41 & 4.19 & 0.07 & not significant \\
BC & 16.73 & 1 & 16.73 & 3.61 & 0.0053 \\
B^2 & 43.92 & 1 & 43.92 & 9.48 & & \\
Residual & 106.58 & 23 & 4.63 & & & \\
Lack of Fit & 99.51 & 19 & 5.24 & 2.96 & & \\
Pure Error & 7.07 & 4 & 1.77 & & & \\
Cor Total & 836.86 & 28 & & & & \\
\hline \hline
\end{tabular}

Succinic acid $=+59.81-(3.94 \times \mathrm{pH})-(1.29 \times$ Crude glycerol $)-(0.097 \times$ Shaking speed $)+(4.09 \mathrm{E}-003 \times$ Crude glycerol $\times$ Shaking speed $)+(0.025 \times$ Crude glyc

Acetic acid $=+3.47-0.049 \times$ Crude glycerol
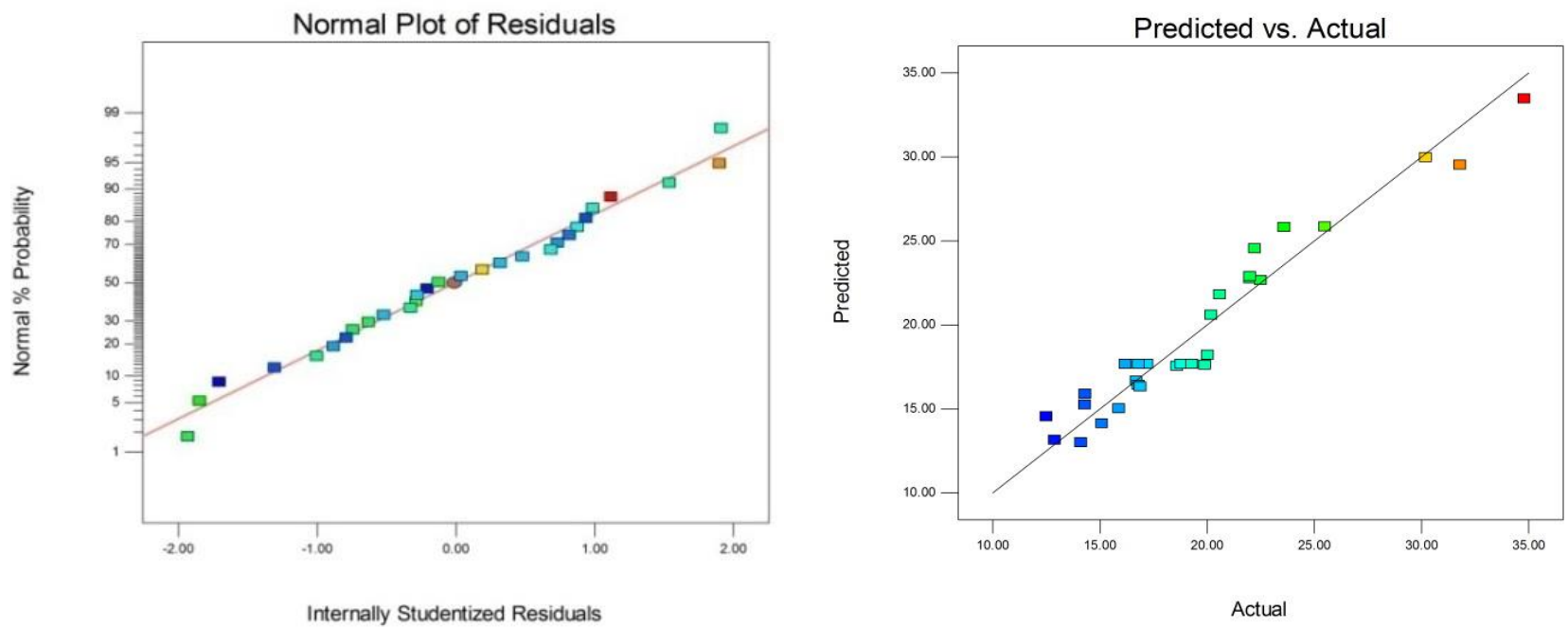

Fig. 3. Plot of residuals (a)Normal plot of probability (\%) versus studentized residuals (b)Scatter graph of the predicted response values versus the actual response values for the succinic acid production.

Fig. 5a shows the effect of the interaction between shaking speed and temperature. The maximum production of succinic acid can be seen to occur at a shaking speed of $150 \mathrm{rpm}$ and temperature of $39{ }^{\circ} \mathrm{C}$, but with a relatively slow decrease as these parameter values are changed. In Fig. 5b, the acetic acid production is a minimum of 1.07 at pH 6.39 and crude glycerol $40 \mathrm{~g} / \mathrm{L}$ and the maximum succinic acid: acetic acid ratio of 31.12. Fig. 6a shows the effect of the interaction between $\mathrm{pH}$ and shaking speed. The maximum production of succinic acid can be seen to occur at pH of 6 and shaking speed of $150 \mathrm{rpm}$, with a fairly slow change as the shaking speed is reduced and a faster change as the $\mathrm{pH}$ is increased. In Fig. $6 \mathrm{~b}$, the acetic acid production is a minimum of 1.35 at pH 6.0 and crude glycerol $40 \mathrm{~g} / \mathrm{L}$ and the maximum succinic acid: acetic acid ratio of 25.50. 
(a)

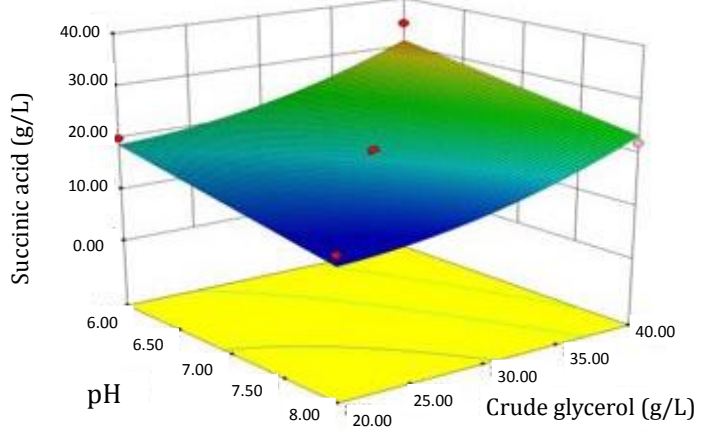

(b)

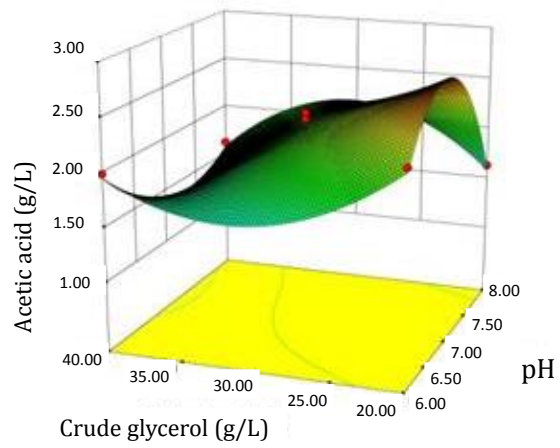

Fig. 4. Response surface 3D graphs for (a) succinic acid production and (b)acetic acid affected by crude glycerol and $\mathrm{pH}$.

(a)

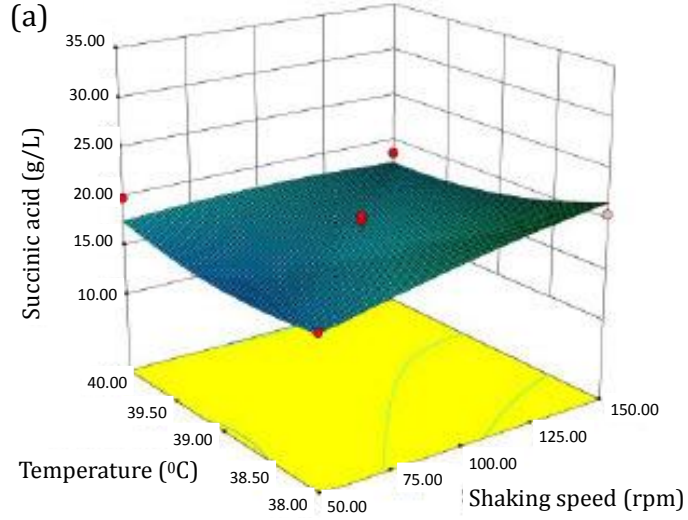

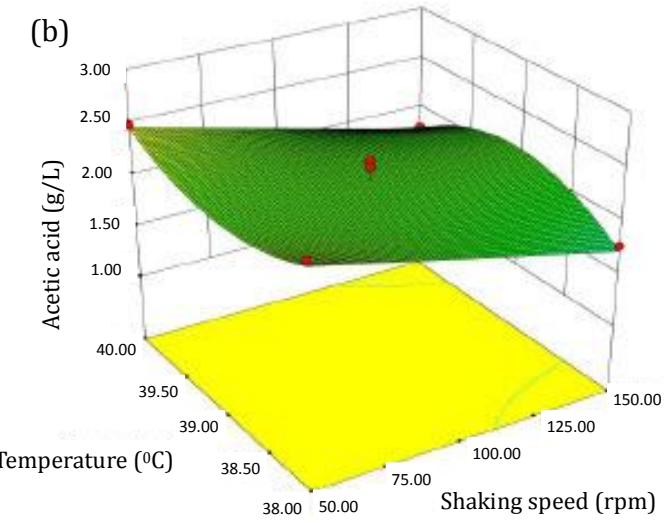

Fig. 5. Response surface 3D graphs for (a) succinic acid production and (b) acetic acid affected by temperature and shaking speed.
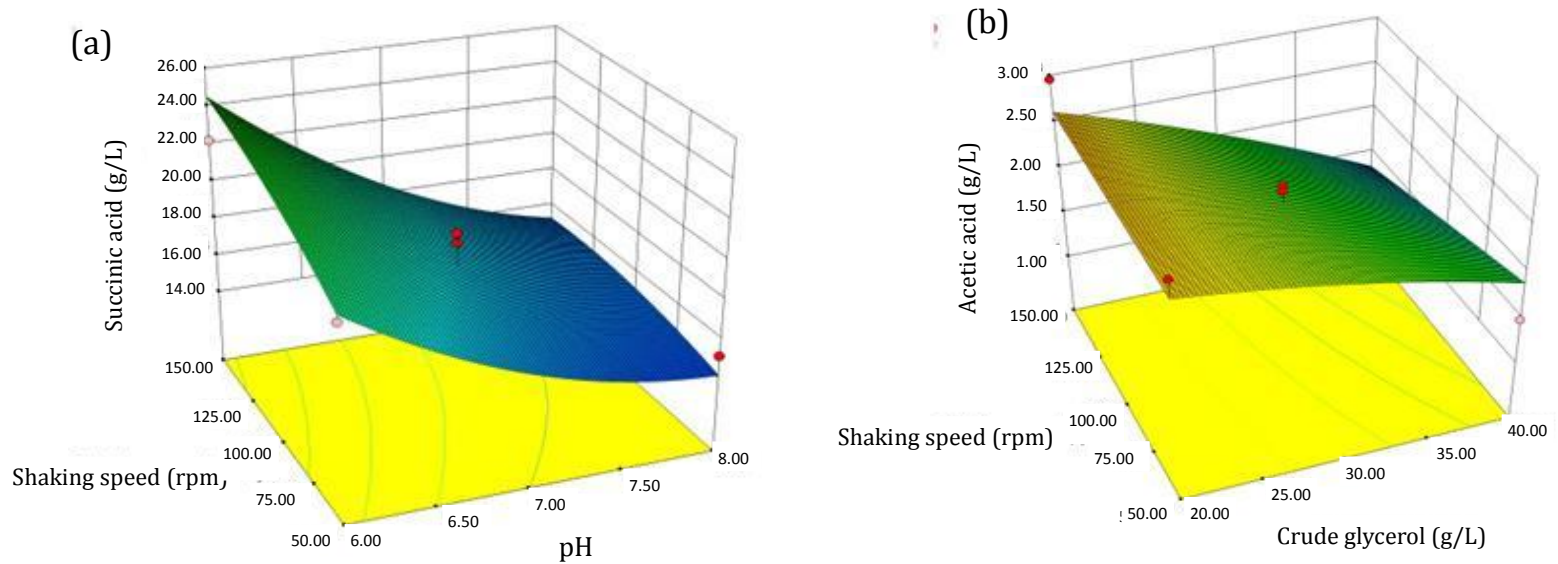

Fig. 6. Response surface 3D graphs for (a) succinic acid production and (b) acetic acid affected by shaking speed and $\mathrm{pH}$.

Fig. 7a shows the effect of the interaction between crude glycerol and shaking speed. The maximum production of succinic acid can be seen to occur at crude glycerol of $40 \mathrm{~g} / \mathrm{L}$ and shaking speed of $150 \mathrm{rpm}$, with rapid changes in succinic acid production as the crude glycerol is reduced and the pH is increased. In Fig. $7 \mathrm{~b}$, the acetic acid production is a minimum of 1.04 at pH 6.40 and crude glycerol $40 \mathrm{~g} / \mathrm{L}$ and the maximum succinic acid: acetic acid ratio of 31.74. The main features of the change in ratios of succinic acid to acetic acid as parameter values were changed can be summarized as follows. We found that the ratios of 
succinic acid to acetic acid ranged from a minimum value of 4.56 at fermentation parameter values (pH 7, crude glycerol $20 \mathrm{~g} / \mathrm{L}$, shaking speed $50 \mathrm{rpm}$, temperature $39{ }^{\circ} \mathrm{C}$ ) to a maximum value of 29.72 at fermentation parameter values ( $\mathrm{pH} 7$, crude glycerol $40 \mathrm{~g} / \mathrm{L}$, shaking speed $150 \mathrm{rpm}$, temperature $39{ }^{\circ} \mathrm{C}$ ) with an average ratio of 13.80. At the optimum fermentation conditions for succinic acid production $(\mathrm{pH}, 6$, crude glycerol $40 \mathrm{~g} / \mathrm{L}$, shaking speed $150 \mathrm{rpm}$, temperature $39{ }^{\circ} \mathrm{C}$ ), the succinic acid/acetic acid ratio was 13.45. This ratio is lower than that previously reported by Lee [16] who found that the ratio using glycerol as substrate was $26: 1$.

(a)

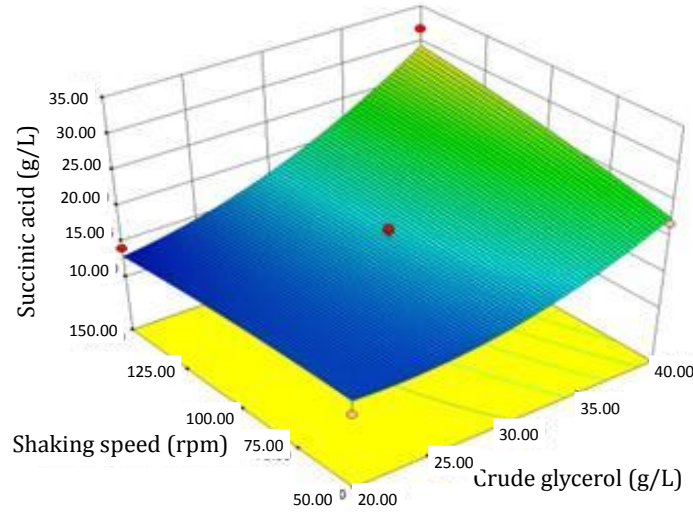

(b)

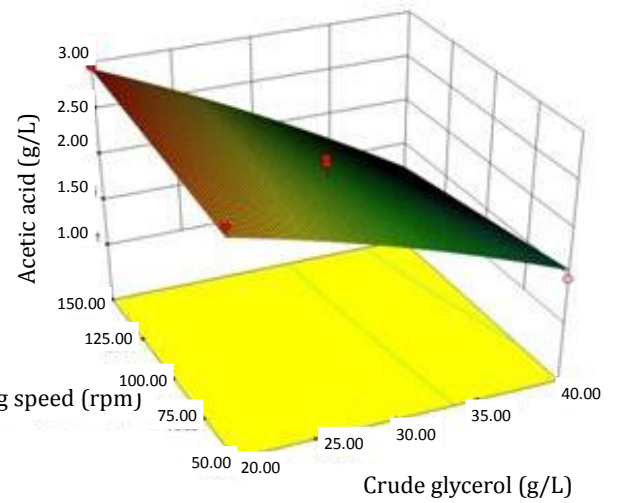

Fig. 7. Response surface 3D graphs for (a) succinic acid production and (b) acetic acid affected by shaking speed and crude glycerol.

We suggest that our experimental results can be explained as follows. Under anaerobic fermentation conditions, an increase in shaking speed would increase the amount of $\mathrm{CO}_{2}$ in the crude glycerol. This should result in an increased diffusion of $\mathrm{CO}_{2}$ into the NaCS/PDMAAC microcapsules which encapsulate the A. succinoproducens. Fermentation studies indicated that succinic acid production was regulated by the level of available $\mathrm{CO}_{2}$ and culture $\mathrm{pH}$ [25]. Previous reports on the metabolic and kinetic studies on $A$. succiniciproducens on a whey substrate have shown that the succinate/lactate ratio was dependent on $\mathrm{pH}$ and $\mathrm{CO}_{2}$ availability. Their reports suggested that high $\mathrm{CO}_{2}$ concentrations and a pH near 6 , rather than 7 , shifted metabolism away from lactate to succinate and acetate at a ratio of 1.8:1 [26]. Therefore, the significance of shaking speed in our model (see Fig. 7) can be understood on the basis of an increase in $\mathrm{CO}_{2}$ concentration in the fermentation broth as the speed is increased. This observation can be explained from the view point of an increased efficiency of enzyme binding to crude glycerol for succinic acid production due tothe fact that in vitro enzyme activities for this system depend on pyruvate-ferredoxinoxidoreductases (PEPCK) which are responsible for converting pyruvate to acetyl-CoA. PEPCKwas implicated as the major $\mathrm{CO}_{2}$-fixing enzyme that generatesoxaloacetate (OAA) which can then be converted to succinic acid by a reductive tricarboxylic acid branch. Both pyruvate-ferredoxinoxidoreductase and PEPCK activity levels respond to $\mathrm{pH}$ and $\mathrm{CO}_{2}$ concentration changes. Based on the kinetic data reported previously, it appears that the fixing of carbon dioxide to PEP is a rate limiting step [27] in the succinic acid production. Therefore by accelerating this reaction it may be possible to increase the affinity PEPCK for carbon dioxide. PEPCK is also generally known as a gluconeogenic enzyme. This function of PEPCK has been observed in a few instances, such as during propionate fermentation by Bacteroides species [28], [29].

\subsection{Validation of the Model}

The experiments and results reported in Sections 3.1-3.3 were obtained in a 1L Duran flask. In this section, we report results designed to test whether the results obtained in the small flask were valid for a stirred tank bioreactor. The reactions were carried out in a batch bioreactor(BioFlow3000, New Brunswick 
Scientific, NJ, USA) with a working volume of $3 \mathrm{~L}$. Carbon dioxide was sparged into the medium at $0.05 \mathrm{vvm}$ continuously throughout the fermentation time. In the bioreactor test, the fermentation parameters were set at the optimal values found for the flask production, namely, crude glycerol, $40 \mathrm{~g} / \mathrm{L}$; shaking speed, 150 $\mathrm{rpm}$; temperature, $39^{\circ} \mathrm{C}$ and $\mathrm{pH}$ 6.0. To validate these fermentation parameters, results from the run of the stirred tank bioreactor in anaerobic batch fermentation were compared with the flask results. The maximal succinic acid production obtained in the bioreactor was $34.66 \mathrm{~g} / \mathrm{L}$ compared with $34.80 \mathrm{~g} / \mathrm{L}$ for the flask experiments. For the flask, the conversion yield was $87 \%$ and ratio of succinic acid to acetic acid was 34:1. For the bioreactor, the conversion yield was $86 \%$ and ratio of succinic acid to acetic acid was $34: 1$. Both sets of experimental results are in good agreement with the predictions of the quadratic regression model.

\section{Conclusion}

This study demonstrated that succinic acid could be produced with little formation of by-product acetic acid by using immobilized A. succiniciproducens cells encapsulated in NaCS/PDMAAC microcapsules with crude glycerol by-product from biodiesel production as a carbon source. The immobilized condition through entrapment has been found to facilitate the purification of succinic acid. It has been shown that the statistical approach of response surface methodology can be used to find optimum conditions for succinic acid production from encapsulated cells under anaerobic conditions. Although the encapsulated cells have been found to be effective, it will be necessary to evaluate their use in more detail, for example, by testing their effective lifetime of use in the production process. Previous studies have shown that $A$. succiniciproducens can efficiently utilize glucose, glycerol, sucrose, maltose, lactose and fructose as carbon sources. It has been shown in these studies that the use of glycerol as a carbon source results in an increased succinic acid yield $(133 \%, \mathrm{~mol} / \mathrm{mol}$ ) and much higher ratio of succinic acid to acetic acid (Gram ratio of 25.8:1) than is obtained with glucose [16]. If succinic production using encapsulated $A$. succiniciproduens is to be increased further, the metabolic flux through the succinate pathway should be examined in more detail. It may be possible, for example, to enhance the succinic production by genetic modification or allosteric activation of enzymes in the metabolic path way. The improved production of succinic acid by $A$. succinoproducens encapsulated in NaCS/PDMDAAC microcapsules has shown the possibility for increased production of bio-succinic acid. Bio-production is one approach that can be used at present to increase succinic acid use in specialty chemical markets. However, the bio-production process is not yet capable of supporting bulk chemical markets. In order to make bio-based succinic acid an economically viable intermediary feedstock for bulk chemical production, it will be necessary to develop inexpensive fermentation and purification processes or for alternative reduction methods to become more expensive, for example, by increased oil prices. All organisms known to naturally produce succinate do so by mixed acid fermentation. Thus, metabolic engineering will be needed to develop methods for diverting flux towards succinic acid and away from undesirable by-products such as acetic acid. This target goal can be reached if the efficiency of the substrate conversion pathway can be improved to a level at which the bio-succinic acid can compete economically with the oil-based succinic acid.

\section{Acknowledgments}

Authors are indebted to a financial grant from Office of Higher Education Commission, Thailand, and Grantno.2554A11902002. The authors appreciate the support of Professor Josef Stockomer, Bremerhaven University of Applied Science, Germany who provided the opportunity for them to carry out this research. They are also grateful to Dr. Elvin J. Moore for helpful suggestions and a critical reading of this manuscript. 


\section{References}

[1] Phalakornkulea, C., Petiruksakula, A., \& Puthavithi, W. (2009). Biodiesel production in a small community: Case study in Thailand. Resour. Conserv. Recy., 53, 129-135.

[2] Ruhal, R., \& Choudhury, B. (2012). Use of an osmotically sensitive mutant of Propionibacterium freudenreichii subspp. shermanii for the simultaneous productions of organic acids and trehalose from biodiesel waste based crude glycerol. Bioresource Technol., 109, 131-139.

[3] Vodnar, D. C., Dulf, F. V., Pop, O. L., \& Socaciu, C. (2013). L (+)-lactic acid production by pellet-form Rhizopus oryzae NRRL 395 on biodiesel crude glycerol. Microb. Cell Fact., 12, 92.

[4] Zeikus, J. G., Jain, M. K., \& Elankovan, P. (1999). Biotechnology of succinic acid production and markets for derived industrial products. Appl. Microbiol. Biotechnol., 51(5), 545-552.

[5] Beauprez, J. J., Mey, M. D., \& Soetaert, W. K. (2010). Microbial succinic acid production: Natural versus metabolic engineered producers. Process Biochemistry, 45, 1103-1114.

[6] Mcconnell, S. (2009). Biobased succinic acid pilot effort underway. Chem. Eng., 116, 13.

[7] Samuelov, N. S., Datta, R., Jain, M. K. \& Zeikus, J. G. (1999). Whey fermentation by Anaerobiospirillum succiniciproducens for production of a succinate-based animal feed additive. Appl. Environ. Microb., 5, 2260-2263.

[8] Bretz, K., \& Kabasci, S. (2012). Feed-control development for succinic acid production with Anaerobiospirillum succiniciproducens. Biotechnol. Bioeng., 109(5), 1187-1192.

[9] Westm, T. P. (2013). Citric acid production by Candida Species grown on asoy-based crude glycerol. Prep. Biochem. Biotechnol., 43, 601-611.

[10] Lee, P. C., Lee, W. G., Lee, S. Y. \& Chang, H. N. (2001). Succinic acidproduction with reduced by-product formation in the fermentation of Anaerobiospirillum succinoproducens using glycerol as a carbon source. Biotechnol. Bioeng., 72, 41-48.

[11] Lee, P. C., Lee, S. Y., \& Chang, H. N. (2010). Kinetic study on succinic acidand acetic acid formation during continous cultures of Anaerobiospirillum succinoproducens grown on glycerol. Bioprocess Biosyst. Eng., 33, 465-471.

[12] Samuelov, N. S., Lamed, R., Lowe, S., \& Zeikus, J. G. (1991). Influence of $\mathrm{CO}_{2}-\mathrm{HCO}_{3}$ levels and pH on growth, succinate production and enzyme activities of Anaerobiospirillum succiniciproducens. Appl. Environ. Microb., 57, 3013-3019.

[13] Song, H., \& Lee, S. Y. (2006). Production of succinic acid by bacterial fermentation. Enzyme Microb. Tech., 39, 352-361.

[14] Tee, W., Korman, T. M., Waters, M. Y., Macphee, A., Jenney, A., Joyce, L. et al. (1998). Three Cases of Anaerobiospirillum succiniciproducens Bacteremia Confirmed by $16 \mathrm{~S}$ rRNA Gene Sequencing. J. Clin. Microbiol., 36(5), 1209-1213.

[15] Lee, J. W., Kim, H. U., Choi, S., Yi, J., \& Lee, S. Y. (2011). Microbial productionof building block chemicals and polymers. Curr. Opin. in Biotechnol., 22(6), 758-767.

[16] Lee P. C., Lee W. G., Kwon S., Lee S. Y., \& Chang H. N. (2000). Batch and continuous cultivation of Anaerobiospirillum succinoproducens for the production of succinic acid from whey. Appl. Microbiol. Biotechnol., 54, 23-27.

[17] Lee, P. C., Lee, S. Y., Hong, S. H., Chang, H. N., \& Park, S. C. (2003). Biologicalconversion of wood hydrolysate to succinic acid by Anaerobiospirillum succiniciproducens. Biotechnol. Lett., 25, 111-114.

[18] Lee, P. C., Lee, S. Y., \& Chang, H. N. (2008). Succinic acid production by Anaerobiospirillum succiniciproducens ATCC 29305 growing on galactose, galactose/glucose and galactose/lactose. Journal of Microbiol Biotechnol., 18, 1792-1796. 
[19] Yu, J., Li, Z., Ye, Q., Yang, Y., \& Chen, S. (2010). Development of succinicacid production from corncob hydrolysate by Actinobacillu ssuccinogenes. Ind. Microbiol. Biotechnol., 37(10), 1033-1040.

[20] Zhang, X., Shanmugam, K. T., \& Ingram, L. O. (2010). Fermentation of glycerol to succinate by metabolically engineered strain Escherichia coli. Appl. Environ. Microbiol., 76(8), 2397-2401.

[21] Zheng, P., Dong, J. J., Sun, Z. H., Ni, Y., \& Fang, L. (2009). Fermentative production of succinic acid from straw hydrolysate by Actinobacillus succinogenes. Bioresource Technol., 100, 2425-2429.

[22] Westman, J. O., Ylitervo, P., Franzén, C. J., \& Taherzadeh, M. J. (2012). Effects of encapsulation of microorganisms on product formation during microbial fermentations. Appl. Microbiol. Biotechnol., 96(6), 1441-1454.

[23] Zhao, Y. N., Chen, G., \& Yao, S. J. (2006). Microbial production of 1, 3-propanediol from glycerol by encapsulated Klebsiella pneumonia. Biochem. Eng. J., 32(2), 93-99.

[24] Box, G. E. P., \& Behnke, D. W. (1960). Some new three level designs for the study of quantitative variable. Technometrics, 2, 455-475.

[25] Podkovyrov S. M., \& Zeikus J. G. (1993). Purification and characterization of phosphoenol puruvate carboxykinase, a carboxylic $\mathrm{CO}_{2}$ fixing enzyme from Anaerobiospirillum succinoproducens. J. Gen. Microbiol., 139, 223-228.

[26] Glassner D. A., \& Datta R. (1992). Process for the production and purificationof succinic acid. US Patent, 5(143), 834.

[27] Laivenieks M., Vieille C., \& Zeikus J. (1997). Cloning, sequencing, and overexpression of the Anaerobiospirillumsucciniciproducensphosphoenolpyruvatecarboxykinase ( $p c k A)$ gene, Appl. Environ. Microbiol., 63, 2273-2280.

[28] Macy, J. M., Ljungdahl, L. G., \& Gottschalk, G. (1978). Pathway of succinate and propionate formation in Bacteroides fragilis. J. Bacteriol., 134, 84-91.

[29] Scardovi, V., \& Chiappini, M. G. (1966). Studies in rumen bacteriology V. Carboxylation of phosphoenolpyruvate in some rumen bacterialstrains and in the cell-free extract of the total rumen flora. Ann. Microbiol. Enzymol., 16, 119-127.

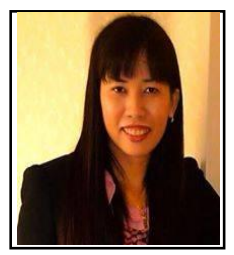

Sasithorn Kongruang received the B.S. degree in agro-industrial technology from King Mongkut's University of Technology North Bangkok, Bangkok, Thailand in 1995. She graduated with M.S. and Ph.D. degrees in bioresource engineering from Oregon State University, USA, in 1999 and 2003, respectively. Her special interest is on advance bioprocess engineering, fermentation technology and industrial microbiology. She recently published an article on growth kinetics of biopigment production by Thai isolated Monascus purpureus in a stirred tank bioreactor, Journal of Industrial Microbiologyand Biotechnology, 2011, 38(1): 93-99. Currently, she is working at the Department of Biotechnology, Faculty of Applied Science, King Mongkut's University of Technology North Bangkok, Thailand.

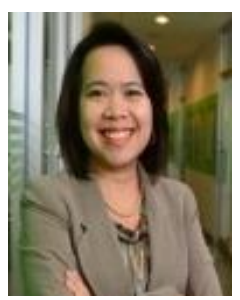

Tawiwan Kangsadan received the B.S. degree in chemical engineering from University of Missouri-Rolla, Rolla, Missouri, USA in 1996. She graduated with M.S. in chemical engineering and petroleum refining from Colorado School of Mines, Golden, Colorado, USA in 2000 and Ph.D. degree in metallurgical and materials engineering (Physico-Chemical Processing) from Colorado School of Mines, Golden, Colorado, USA in 2004. Her special 
interest is in thermal and non-thermal preservation, transformation and separation in food processing using High Electrical Field Pulse Technique; and biodiesel production using ultrasonication and microwave methods. Currently, she is working at the Chemical Engineering Program, Department of Mechanical and Process Engineering, The Sirindhorn International Thai-German Graduate School of Engineering, King Mongkut's University of Technology North Bangkok, Thailand. 